\title{
The effect of water deprivation upon shock elicited aggression in the white rat
}

\author{
WILEY HAMBY and D. D. CAHOON* \\ Auburn University, Auburn, Ala. 36830
}

Aggressive responses were recorded for male albino rats under conditions of shock stimulation only and water deprivation plus shock. Results indicated that shock delivered while the $S$ was water deprived elicited fewer aggressive responses than shock alone and that merely restraining the $S$ did not elicit aggressive responses.

A recent investigation by Cahoon, Crosby, Dunn, Herrin, Hill, \& McGinnis (1971) studied the effects of food deprivation upon shock-elicited aggression in the white rat. Results seemed to indicate that deprivation paired with shock produced more aggressive responding than shock presented alone. Further, the number of aggressive responses was found to vary positively with amount of deprivation. The present experiment was designed to determine the effect of water deprivation plus shock upon aggressive responding in the white rat. SUBJECTS

The Ss were 10 experimentally naive male Sprague-Dawley rats, approximately 80 days old at the beginning of the experiment. APPARATUS

Equipment included a constant-current shocker and two rat-restraining devices similar to the apparatus described by Azrin, Rubin, \& Hutchison (1968). Specifically, the rat-restraining device consisted of a Plexiglas tube, $33^{1 / 2} \times 7^{1 / 2} \times 61 / 2 \mathrm{~cm}$. This chamber was equipped with an adjustable side panel which secured the animal and restricted turning and twisting movements during the delivery of shocks. The tube was mounted on a Plexiglas base, with masking tape covering the sides and bottom of the tube and with a fitted cardboard strip fixed to the top of the chamber. At the rear of the apparatus, a Plexiglas panel, through which the $S$ 's tail extended, prevented backing out of the chamber. A tail-restraining bar was situated immediately behind the panel. During the experimental sessions, the S's tail was secured to the bar with adhesive tape. The target toward which aggression could be directed was movable and, in operation, was adjusted to a distance of $1 \mathrm{~cm}$ from the $S$ 's nose. Biting and pulling the target for a distance of $1 / 3 \mathrm{~cm}$ operated a microswitch, transmitting a pulse to the recording device. This was defined as an aggressive response.

*Requests for reprints should be sent to D. D. Cahoon, Department of Psychology, Au burn University, Auburn, Ala. 36830 .

\section{PROCEDURE}

Prior to the experiment, each $S$ was placed in the apparatus for $30 \mathrm{~min}$ to allow for adaptation to the chamber. Only one $S$ bit the target (one response) during the adaptation period; thus, pretest aggression was considered negligible. The $\mathrm{Ss}$ were then divided into two groups of five rats each and marked for identification. One group was designated as "shock only" (Group S), and the remaining group as "deprivation plus shock" (Group $D+S$ ). Prior to the initiation of the experiment, the $D+S$ group was deprived of water for $24 \mathrm{~h}$. Following each session, the $D+S$ Ss were allowed free access to water for $30 \mathrm{~min}$ and then deprived for $24 \mathrm{~h}$ prior to the next experimental session. All sessions were conducted at 24-h intervals, with the exception of the first and second, which were separated by an interval of $48 \mathrm{~h}$ due to an equipment failure. Each 30-min session consisted of a 15-min no-shock control period and a 15-min treatment period. The control and treatment periods were alternated in position for each $S$ on successive days. During the treatment phase, shock was administered for $.5 \mathrm{sec}$ with a 3 -sec intershock interval. Shock intensities ranged from 1.6 to $4 \mathrm{~mA}$, with intensities equated for each $S$. Nine sessions were conducted, with a total of 300 stimulations administered during each period.

\section{RESULTS AND DISCUSSION}

Elicited aggression was measured by the number of biting and pulling responses for both the $\mathbf{S}$ and $D+S$ groups. A summary of these data is given in Table 1.

Comparison of the sums of the no-shock control periods (NS) with the sums of the treatment periods (S), by means of the Wilcoxon matched-pair test, yielded significance beyond the .001 level of probability. Thus, it can be concluded that shock, rather than restriction in the apparatus, was primarily responsible for the biting behavior. The $S$ and $\mathrm{D}+\mathrm{S}$ groups were compared with respect to their treatment sums by means of the Wilcoxon-Mann-Whitney $t$ test. Significance was recorded at the .05 level, with the greater number of responses elicited from the group exposed to shock without deprivation.

The finding that water deprivation plus shock elicits fewer aggressive responses than shock alone is seemingly in contrast with those investigations which have found that food deprivation increases aggression (e.g., Davis, 1933; Azrin, Hutchison, \& Hake, 1960; Cahoon et al, 1971). However, it must be noted that a direct comparison between the aggressive effects of food and water deprivation is complicated by a lack of uniformity among the studies to be compared. Further research in which the hunger and thirst components are varied within a single experimental framework would seem to be indicated.

\section{REFERENCES}

AZRIN, N. H., HUTCHISON, R. R., \& HAKE, D. F. Extinction-induced aggression. Journal of the Experimental Analysis of Behavior, 1966, 9, 191-204.

AZRIN, N. H. RUBIN, H. B. \& HUTCHISON, R. R. Biting attack by rats in response to aversive shock. Journal of the Experimental Analysis of Behavior, $1968,11,633-639$.

CAHOON, D. D., CROSBY, R. M., DUNN, S., HERRIN, M. S., HILL, C. C., \& MCGINNIS, M. The effect of food deprivation on shock-elicited aggression in rats. Psychonomic Science, 1971, 22, 43-44

DAVIS, F. C. The measurement of aggressive behavior in laboratory rats. Journal of Genetic Psychology, 1933, 43, 213-217.

Table 1

Raw Data Sums of Aggressive Responses Recorded for Organisms Shocked But Not Deprived (S), and Organisms Shocked While Water Deprived (D + S). Shock (S) and no shock (NS) periods are recorded for both sets of Ss.

\begin{tabular}{|c|c|c|c|c|}
\hline \multirow[b]{2}{*}{ Ss } & \multicolumn{2}{|c|}{ Shock Only } & \multicolumn{2}{|c|}{$\begin{array}{l}\text { Deprivation } \\
\text { Plus Shock }\end{array}$} \\
\hline & $s$ & NS & $\mathbf{s}$ & NS \\
\hline 1 & 131 & 0 & 8 & 0 \\
\hline 2 & 14 & 3 & 18 & 1 \\
\hline 3 & 227 & 3 & 13 & 0 \\
\hline 4 & 20 & 1 & 13 & 0 \\
\hline 5 & 66 & 0 & 30 & 0 \\
\hline Total & 458 & 7 & 82 & 1 \\
\hline
\end{tabular}

